\title{
ATHLETIC IDENTITY OF STUDENTS ACTIVELY INVOLVED IN SPORTS AND ITS RELATIONSHIP WITH INDUCED STRESS
}

\author{
Vinga Indriuniene \\ Lithuanian Sports University, Lithuania
}

\begin{abstract}
The expression of the athletic identity in academic environments may become a stress-reducing and a stress-enhancing factor depending on the conditions of the environment when expressing one's athletic identity (Chen et al., 2010).Methods. 214 students (105 females and 109 males) took part in the research. All of them were first year students of the first level of studies (i.e. BA studies) at Lithuanian Sports University. All the students were actively practicing sports. Their age ranged from 18 to 25 with the age average of 19.24 (0.76). The study made use of questionnaires: Reeder Stress Assessment Scale and Athletic Identity Questionnaire (AIQ).Conclusions. The stress levels experienced by students actively practicing sports and possessing a more prominent athletic identity yet not going for results in sports are lower than those experienced by students with a less prominent athletic identity.
\end{abstract}

Keywords: athletic identity, stress, students, sport.

\section{Introduction}

Individuals may choose a wide variety of fields for the development of their identity such as family, job, science, arts or sports. Athletic identity is closely related with physical activity, sports or sports activity within which the personal identity is created (Houle et al, 2010). Athletic identity is one of the lifelong developing parts of the self-reflection of the personality which shows to what extent an individual relates him/herself with physical activity or sports activity (Brewer et al., 1993; Anderson, 2007). Athletic identity is also perceived as the unique fulfillment of one's physical Me by taking a role in sports and by the establishment of one's identity with sports and a sports community (Banayi et al., 2014).

For an individual, sport is turning into a social environment where $\mathrm{s} / \mathrm{heis}$ competing with others and going for results in sports in a specific branch of sports in order to fulfill oneself and to gain recognition of the society (Esfahani et al., 2014). It has been observed that strong athletic identity has a prominent impact on the personal life of an individual (Banayi et al., 2014). The strong athletic identity undertaken by an individual facilitates social integration and consequently increases self-confidence (Finch, 2009). Yet, excessively manifested athletic identity of the young people actively going in for sports may bear a negative impact on the psychological and physical health of an individual (Houle et al., 2010). 
Young people with a more prominently expressed athletic identity see sport as one of the best ways of self-expression and self-fulfillment (Finch, 2009). Hence a youngster with a prominently expressed athletic identity may be experiencing a crisis of identity; this crisis consequently evolves into the increased induced stress which is also manifested in other social environments. Students representing a team and possessing a prominently expressed athletic identity will be experiencing more stress related not only with the academic activity but also with their sports activity (Chen et al., 2010). Even the successful development of a career in sports inevitably features such additional stressors as failures or losses in sport competitions, lack of time, poor relationship among team members, high demands of the coach, etc. Yet further stress may be inflicted by a combination of professional sports and studies (Chen et al., 2010; Houle et al., 2010).

On the other hand, athletic identity may also decrease the stress experienced by students; students possessing a more prominent athletic identity and fulfilling themselves in a sports activity will not be experiencing stress as long as they have no obligations to a team, and the levels of stress will be reduced since physical activity with no commitment to a team will have the impact of a stress-reducing factor. Hence the expression of the athletic identity in academic environments may become a stress-reducing and a stress-enhancing factor depending on the conditions of the environment when expressing one's athletic identity (Chen et al., 2010). In this context, the issue of the interrelation of the athletic identity and the suffered stress in sportspeople is seen as an area of major academic interest.

The aim of the research is to establish the athletic identity of first year students actively practicing sports and the relationship between the athletic identity and the experienced stress. Consequently, by combining quantitative data and qualitative research-based insights, the present research strives to contribute to the research of the impact of professional sports on full time students.

\section{Research Methodology}

The research was conducted during the spring semester of the academic year 2013/2014 in the course of Personal Identity classes at Lithuanian Sports University, Kaunas, Lithuania.

214 students (105 females and 109 males) took part in the research. All of them were first year students of the first level of studies (i.e. BA studies) at Lithuanian Sports University. All the students were actively practicing sports. Their age ranged from 18 to 25 with the age average of $19.24(0.76)$. The participants of the research represented various study programs of the University. They were divided into two groups of the research sample: Group One consisting of 121 students actively practicing sports (i.e. students practicing 
sports at least 2 or 3 times per week) but not seeking to produce officially recognized results including 61 females $(50.4 \%)$ and 60 males $(49.6 \%)$ and Group Two represented by 93 students actively practicing sports and going for officially recognized results ( 1 or 2 practice sessions daily), among whom there were 44 females $(47.3 \%)$ and 49 males $(52.6 \%)$.

The participants of the research had to fill in questionnaires during the classes of the Personal Identity subject. The participants of the research were fully aware that the questionnaire was anonymous.

Methods of the research. Reeder Stress Assessment Scale (Reeder et al., 1968) commonly used to measure the subjectively perceived stress was employed to quantify psychological stress. The stress levels were assessed by research participants providing evaluations for seven statements defining the way the research subject typically feels. The assessment was quantified in the range from 1 to 4 , and the points were added up. The obtained result which may potentially range from 7 to 28 indicates the level of stress as perceived by an individual; here specifically 21 to 28 means 'no stress', 15 to 20 stands for 'nervous strain' (intermediate state) and 7 to 14 signifies a state of stress. The Cronbach alpha of the scale is 0.814 .

For the assessment of athletic identity, the Athletic Identity Questionnaire for Youth was employed (Athletic Identity Questionnaire; Anderson et al., 2007). The questionnaire consists of 40 statements on the grounds of which the four primary components of the athletic identity are measured:

- $\quad$ sportscompetence (for example, I believe I would be able to take part in numerous sporting activities if I made sufficient effort and had enough practice);

- $\quad$ one's looks (for example, I look sportive, i.e. I look like a person doing exercises);

- importance of physical activity to the concerned individual (for example, I prefer being physically active to lying on the bed or watching $T V$ while sitting on a couch);

- $\quad$ social encouragement (support) to be physically active (for example, My parents incite me to exercise and/or be physically active).

The agreement or disagreement with the statements was measured in a scale ranging from 1 to 5 where ' 1 ' stood for complete disagreement with the statement, ' 2 ' meant partial disagreement with the statement, ' 3 ' showed neither agreement nor disagreement with the statement, '4' represented partial agreement with the statement and ' 5 ' indicated complete agreement with the statement. The higher values in the scale thus represented a more prominent athletic identity (or a specific component of athletic identity) of students. The Cronbach alpha of the scales ranged from 0.794 to 0.901 .

The groups of the participants of the research were drafted on the grounds of the median of the scale of their general athletic identity (less prominently versus more prominently expressed athletic identity levels). 
The relationship of the qualitative features were assessed by employing chi square $(\chi)^{2}$ criterion andtcriterion for independent samples. Differences were treated as statistically important if $p$ was discovered to be $<0.05$. Calculations were performed with SPSS Statistics 21 Version.

\section{Research results}

The research also sought to explore the athletic identity of students and the manifestation of its specific components. On the grounds of the Athletic Identity Model by C. B. Anderson (2004), the athletic identity consists of four essential constituting elements: the evaluation of the physical abilities of oneself (competence), the looks (sportive versus non-sportive), the importance of physical activeness and the extent of the social support (incitement) to do sports or to be physically active. When taking measurements of the sports competence, looks and the importance of physical activeness, the highest values of all the research subjects were recorded. It was also established in what cases the values of the constituent parts of encouragement were the lowest.

The results of the research showed that the first year university students going for results in sports exhibit statistically significantly more prominent athletic identity in comparison with those students who do not go for officially recognized events in sports (see Table 1). The differences are observed between the groups and also specifically when comparing males and females $(t, p<0.01)$.

Table 1. Manifestation of athletic identity of first year students actively practicing sports

\begin{tabular}{|l|c|c|c|c|c|c|c|}
\hline \multirow{2}{*}{ Athletic identity } & \multicolumn{2}{|c|}{$\begin{array}{c}\text { Not going for } \\
\text { results in sports } \\
\mathrm{n}=121\end{array}$} & $\begin{array}{c}\text { Going for results in } \\
\text { sports } \\
\mathrm{n}=93\end{array}$ & $\mathrm{t}$ & $\mathrm{p}$ \\
\cline { 2 - 8 } & Mean & SD & Mean & SD & & \\
\hline Athletic identity & 3.63 & 0.52 & 4.61 & 0.42 & -4.70 & $\mathbf{0 . 0 0 0 1}$ \\
\hline Components of athletic identity: & 4.03 & 0.81 & 4.78 & 0.59 & -3.38 & $\mathbf{0 . 0 0 0 1}$ \\
\hline Competence & 3.79 & 0.96 & 4.65 & 0.74 & -4.09 & $\mathbf{0 . 0 0 0 1}$ \\
\hline Looks & 3.59 & 0.87 & 4.92 & 0.63 & -4.76 & $\mathbf{0 . 0 0 0 1}$ \\
\hline Importance & 3.24 & 1.24 & 3.74 & 0.79 & -3.02 & $\mathbf{0 . 0 0 0 1}$ \\
\hline Encouragement (Parents) & 2.91 & 0.79 & 3.84 & 1.14 & -3.21 & $\mathbf{0 . 0 0 0 1}$ \\
\hline Encouragement (Peers) & 3.11 & 1.31 & 4.31 & 1.07 & -4.06 & $\mathbf{0 . 0 0 0 1}$ \\
\hline Encouragement (Other adults) & 3.07 & 0.92 & 4.02 & 0.68 & -3.66 & $\mathbf{0 . 0 0 0 1}$ \\
\hline Encouragement (General) & & & & & \\
\hline
\end{tabular}

The more prominently expressed athletic identity is also discovered when specific constituent parts of athletic identity are considered. Students going for results in sports assessed their competences in sports, their sportive looks and the importance of sports and physical activity in their lives much more positively (all of these differences are statistically significant); they claimed they had been experiencing stronger social support from their environment including their parents, friends and other adults in comparison with the support which the 
students not going for results in sports claimed to be receiving. This difference is also statistically significant.

Having explored the stress suffered by students it was established that 61 $(28.5 \%)$ students actively involved in sports activities were not experiencing stress, 88 (41.1\%) individuals were feeling nervous strain (i.e. the intermediate state of stress) whereas $65(30.4 \%)$ students were facingthestateofstress (see Table 2). Besides, it was established that the stress experienced by students maintaining intense sporting activity and going for results in sports is statistically significantly more prominent than the stress which the students not going for results in sports were undergoing.

Table 2. Stress experienced by first year students actively involved in sports

\begin{tabular}{|l|c|c|c|c|c|c|}
\hline \multirow{3}{*}{$\begin{array}{c}\text { Students actively practicing } \\
\text { sports }\end{array}$} & \multicolumn{6}{|c|}{ Suffered stress } \\
\cline { 2 - 7 } & $\begin{array}{c}\text { Not experiencing } \\
\text { stress }\end{array}$ & Nervous strain & \multicolumn{2}{|c|}{ State of stress } \\
\cline { 2 - 7 } & $\mathrm{n}$ & per cent & $\mathrm{n}$ & per cent & $\mathrm{n}$ & per cent \\
\hline Going for results in sports & 12 & 12.9 & 42 & 45.2 & 39 & 41.9 \\
\hline Not going for results in sports & 49 & 40.5 & 46 & 38.0 & 26 & 21.5 \\
\hline
\end{tabular}

"Differences between groups: $x^{2}=16.02 ; d f=2 ; p=0.0001$

During the research, it was established that athletic identity is related with the stress experienced by students. Besides, differences between the groups of students going versus not going for results in sports may thus be highlighted (see Table 3).

Table 3. Comparison of the manifestation of the suffered stress in students actively practicing sports: less prominently vs. more prominently expressed athletic identity

\begin{tabular}{|c|c|c|c|c|c|c|}
\hline \multirow{3}{*}{$\begin{array}{l}\text { Students actively practicing } \\
\text { sports }\end{array}$} & \multicolumn{4}{|c|}{ Groups of athletic identity } & \multirow{3}{*}{$\mathrm{t}$} & \multirow{3}{*}{$\mathrm{p}$} \\
\hline & \multicolumn{2}{|c|}{$\begin{array}{l}\text { Less prominently } \\
\text { expressed }\end{array}$} & \multicolumn{2}{|c|}{$\begin{array}{l}\text { More prominently } \\
\text { expressed }\end{array}$} & & \\
\hline & Mean & $\mathrm{SD}$ & Mean & SD & & \\
\hline Going for results in sports, $n=93$ & 2.69 & 0.53 & 3.12 & 0.74 & 5.01 & 0.0001 \\
\hline $\begin{array}{l}\text { Not going for results in sports, } \\
n=121\end{array}$ & 2.95 & 0.81 & 2.57 & 0.69 & 4.97 & 0.0001 \\
\hline
\end{tabular}

The results of the research revealed that the students not going for results in sports who are actively practicing sports and whose athletic identity is expressed less prominently are subjectively experiencing worse levels of stress than the students with a more highlighted athletic identity. Meanwhile, to the contrary, students actively practicing sports and going for results are subjectively strained by higher levels of stress if their athletic identity is manifested more prominently in comparison with the students with a less prominent athletic identity. 


\section{Discusion}

The present research also corroborates the results obtained by other researchers showing that the manifestation of the personal athletic identity may be twofold. It was observed that physical activeness is related with lower levels of stress (Williams, 2008) and that physically active individuals are more selfconfident; their self-esteem is also higher (Shaffer, Wittes, 2006). It is likely that the lower rate of stress experienced by students whose athletic identity is more prominently expressed and who are actively going in for sports without seeking results in sports is determined by their higher levels of physical activity and consequent superior self-confidence (Finch, 2009; Riemel, 2009).

On the other hand, the students with a more prominently expressed athletic identity seeking results in sports and having commitments in the academic environment while doing their studies undergo higher levels of stress than the students whose activity is restricted to the academic performance (Chen et al., 2010; Finch, 2009; Lally, Kerr, 2005). It is likely that those students who have ambitions in sports encounter such stress-inducing factors as the expectations of their environment concerning their achievements both in sports and studies; that is why students with ambitions in both sports and studies suffer from higher levels of pressure induced by their surroundings. These individuals also have more modest time resources since they have to deal with their commitments in the academic community as well as in the sports community. Other stressinducing factors are related with victories and losses in sports in the context of the highly taxing workloads incurred in the process of studies. Even though the athletic identity and the feeling of being part of a team are of positive influence to the first year students while adapting to the new environment, yet these factors act as an additional stressor in the course of studies. Furthermore, students practicing sports and having high amounts of training practices and competitions tend to skip public events of the student community, they travel a lot, and, upon experiencing injuries, they get detached from public activities and sports. They ultimately start experiencing more stress than students having no prominent athletic identity (Lally, Kerr, 2005).

Athletic identity also has a positive impact on the psychosocial health of an individual (Esfahani et al., 2014; Valente, 2004). According to academic researches, athletic identity has a positive impact on studying sportspeople as it boosts their self-confidence and increases their social integration. However, at some time, an internal conflict between the matters of sports and academic affairs is turning into a major hazard.

Athletic identity is a major source of self-expression among first year students (Finch, 2009); that is why active sportspeople do their best so that to combine sports and academic affairs (Chen et al., 2010; Finch, 2009; Wolniak et al., 2001). Students will likely experience higher levels of sports and studiesrelated stress if they aspire for high results in sports. Students with ambitions in 
sports possessing more prominent athletic identity will have their social integration facilitated at the beginning of their studies; however, already during the first year of studies, it will result in additional stress which is further worsened by the stressors stemming from the requirements imposed by the course of academic studies (Brewer et al., 1993; Miller, 2009). On the other hand, physical activeness and sports will serve the students not going for results in sports as a stress-reducing factor on condition that the students have developed a more prominent athletic identity (Miller, 2009).

The research presupposes the idea that students going for results in sports belong to the group of individuals suffering from enhanced risks of experiencing stress or emotional strain; this is extremely prominent in the students with a stronger athletic identity, i.e. the students who identify themselves with the sports environment rather than with any other social area or activity.

\section{Conclusions}

1. The stress suffered by students actively involved in sports activities and going for results in sports is more prominent than the stress experienced by the students not going for results in sports.

2. The athletic identity of students actively involved in sports and going for professionally recognized results in sports is more prominently expressed than the athletic identity of students not going for results in sports.

3. The stress levels experienced by students actively practicing sports and possessing a more prominent athletic identity yet not going for results in sports are lower than those experienced by students with a less prominent athletic identity. However, students possessing a more prominent athletic identity actively involved in sports activity and seeking results in sports are experiencing higher levels of stress than the students with less prominent levels of athletic identity.

\section{References}

Anderson C. B. (2004).Athletic identity and its relationto exercise behavior: scale development and validation. Journal of Sport and Exercise Psychology, 26(1), 39-56.

Anderson, C. B., Masse, L. C., Hergenroeder, A. C. (2007). Factorial and Construct Validity of the Athletic Identity Questionnaire for Adolescents. Medicine and Science in Sports and Exercise, 39 (1), 59-69.

Banayi, N., Nikbakhsh, R., \& Zargar, T. (2014). The Relationship between Aggressions with Athletic Identity on Shiraz Team Sports. Bulletin of Environment, Pharmacology and Life Sciences, Vol 3 (IV), 57-60.

Brewer, B.W., Van Raalte, J.L., \& Linder, D.E. (1993). Athletic Identity: Hercules' Muscles or Achilles Heel? International Journal of Sport Psychology, 24, 237-254.

Chen, S., Snyder, S., \&Magner, M. (2010). The Effects of Sport Participation on StudentAthletes' and Non-Athlete Students' Social Life and Identity. Journal of Issues in Intercollegiate Athletics, 3, 176-193. 
Esfahani, A. R. N., Khorzoghi, M.B., \& Ahmadi, E. (2014). Relationship between Social Intelligence with Athletic Identity among Wushu Athletes. Scholars Journal of Arts, Humanities and Social Sciences, 2(3B), 428-433.

Finch, B. (2009). Investigating College Athletes' Role Identity and Self-efficacy for Career Decision-making. International Journal of Sport Management, 10, 427-435.

Goštautas, A. (1999). Psichologiniai streso aspektai. Sveikata, 6, 55-58.

Houle, J.L.W., Brewer, B.W. \& Kluck, A.S. (2010) Developmental Trends in Athletic Identity: A Two-part Retrospective Study. Journal of Sport Behavior33(2): 146-159.

Lally, P.S., \&Kerr, G.A. (2005). The Career Planning, Athletic Identity, and Student Role Identity of Intercollegiate Student Athletes. Research Quarterly for Exercise and Sport, $76,275-285$.

Miller, K. (2009). Sport-related Identities and the "Toxic Jock." Journal of Sport Behavior, 32(1), 69-91.

Reeder, L.G., Chapman, J.M., \&Coulson, A.H. (1968).Socioenvironmental stress, tranquilizers and cardiovascular disease.Proceedings of the Excerpta Medica International Congress Series, 182, 226-238.

Riemel, L. (2009). Sportliche Identität der Studenten im ersten Jahr. Zeitschrift für Soziologie, 4, 45-65.

Shaffer, D.R., \&Wittes, E. (2006). Women's Precollege Sports Participation, Enjoyment of Sports, and Self-esteem. Sex Roles, 55(3/4), 225-232.

Valente, L. (2004). What Can We Learn from the Student-athlete? Phi Kappa Phi Forum, 84(4), 14.

Williams, J. (2008). Mental Health in Young Adultsand its Relation with Self-esteem. JournalofSport, 5,11-19.

Wolniak, G.C., Pierson, C.T., \& Pascarella, E.T. (2001). Effects of Intercollegiate Athletics Participation on Male Orientations toward Learning. Journal of Collegiate Student Development, 42(6), 604-624. 